\title{
STATUS OF 3.9 GHZ SUPERCONDUCTING RF CAVITY TECHNOLOGY AT FERMILAB*
}

\author{
E. Harms, T. Arkan, L. Bellantoni, H. Carter, H. Edwards, M. Foley, T. Khabiboulline, D. Mitchell, \\ D. Olis, A. Rowe, N. Solyak, Fermilab, Batavia, IL 60510, U.S.A.
}

\begin{abstract}
Fermilab is involved in an effort to assemble $3.9 \mathrm{GHz}$ superconducting RF cavities into a four cavity cryomodule for use at the DESY TTF/FLASH facility as a third harmonic structure. The design gradient of the cavities is $14 \mathrm{MV} / \mathrm{m}$. This effort involves design, fabrication, intermediate testing, assembly, and eventual delivery of the cryomodule. We report on all facets of this enterprise from design through future plans. Included will be test results of single 9-cell cavities, lessons learned, and current status.
\end{abstract}

\section{INTRODUCTION}

Fermilab has entered into an agreement with DESY to provide a cryomodule containing 4-3.9 $\mathrm{GHz}$ superconducting RF cavities to be placed in TTF/FLASH. These cavities are TM010 structures designed to linearize the accelerating gradient of the $1.3 \mathrm{GHz}$ accelerating cavities in this accelerator, thus providing improved longitudinal emittance. The required operating gradient is $14 \mathrm{MV} / \mathrm{m}$. Table 1 contains a list of parameters.

As a byproduct, another goal of this project is to develop SCRF infrastructure at Fermilab by designing and assembling the necessary components including:

- Cryomodule for 4 cavities

- 4 (+2 spare) dressed cavities with couplers

- Tuners, magnetic shielding, assembly tooling

- Surface processing infrastructure (BCP, HT, HPWR)

- Apparatus and infrastructure for vertically testing single undressed cavities

- Horizontal test cryostat and testing infrastructure for individual dressed cavities including main input coupler

- Cavity string and cryostat assembly infrastructure

- Shipping equipment for cryomodule transport to DESY.

With the design effort virtually complete, effort has turned towards fabrication and testing. It is intended that this work will be completed during late 2007 and the cryomodule delivered to DESY early in 2008.

\section{CAVITIES}

Six $3.9 \mathrm{GHz}$ cavities have now been fabricated. Four more are in various stages of construction. A summary can be found in Table 2. The first two are prototypes and are not envisioned to be made operational. Cavity \#1 is

*Work supported by the U.S. Department of Energy under contract No. DE-AC02-07CH11359.
Table 1: Parameter List

\begin{tabular}{|l|l|}
\hline Number of Cavities & 4 \\
\hline Active Length & 0.346 meter \\
\hline Gradient & $14 \mathrm{MV} / \mathrm{m}$ \\
\hline Phase & $-179^{\circ}$ \\
\hline $\mathrm{R} / \mathrm{Q}$ & $750 \Omega$ \\
\hline $\mathrm{E}_{\text {peak }} / \mathrm{E}_{\text {acc }}$ & 2.26 \\
\hline $\mathrm{B}_{\text {peak }}\left(\mathrm{E}_{\text {acc }}=14 \mathrm{MV} / \mathrm{m}\right)$ & $68 \mathrm{mT}$ \\
\hline $\mathrm{Q}_{\text {ext }}$ & $9.5 \mathrm{X} \mathrm{10^{5 }}$ \\
\hline BBU Limit for HOM, Q & $<1 \times 10^{5}$ \\
\hline Total Energy & $20 \mathrm{MeV}$ \\
\hline Beam Current & $9 \mathrm{~mA}$ \\
\hline Forward Power & $11.5 \mathrm{~kW}$ \\
\hline Coupler Power & $45 \mathrm{~kW}$ \\
\hline
\end{tabular}

now being used to prototype helium vessel welding. Cavity \#2 underwent vertical testing, but was limited by heating in the Higher Order Mode (HOM) coupler areas. Post-test visual inspection revealed fractures at the weld joints of the Formteils within the HOM's. Analysis has concluded that the failures were due to high stresses induced by overheating of the Formteil when power is applied, with multipacting being a probable cause. Finite element analysis (FEA) of the Formteil indicates maximum thermal stresses at the exact same location where the fracture occurred. More details on analysis and remediation is reported elsewhere at this conference [1]. Cavities \#3 and \#4 have undergone extensive vertical testing and are awaiting welding into helium vessels. Both cavities successfully achieved gradients of $23 \mathrm{MV} / \mathrm{m}$ or better.

\section{Fabrication}

Material to construct a total of ten $3.9 \mathrm{GHz}$ cavities has been procured. All component parts and end tube subassemblies were fabricated under the direction of Fermilab personnel. Cavities \#3 through \#6 were assembled and welded at Jefferson Lab using welded end subassemblies provided by Fermilab.

The first six cavities contain a 2-leg Formteil design. Modification involving removal of $3 \mathrm{~mm}$ of the Formteil tip was done following the discovery made on Cavity \#2. Cavities \#3 and \#4 contain such trimmed pieces. Cavity \#3's was done is situ following initial vertical testing.

Cavities \#7 and \#8 will be assembled at Fermilab using a revised single post Formteil design [1]. The single post Formteils were welded into the HOM housing at DESY.

\section{Processing}

All cavities undergo a standard protocol of surface processing including Buffered Chemical Processing (BCP), high temperature hydrogen degasification bake, and High Pressure Rinse (HPR) prior to initial tests. This 
sequence is modeled after the DESY BCP processing cycle.

Upon completion of fabrication, cavities are degreased and cleaned in the clean room at the A0 SCRF facility then sent to the Technical Division's IB4 building for mechanical inspection and initial RF tuning.

Following this, each cavity undergoes a $20 \mu \mathrm{m}$ outside etch followed by a bulk $80 \mu \mathrm{m}$ inside etch using 1:1:2 BCP. All BCP etches occur at Argonne National Laboratory's Building 203 Room G-150 facility and are carried out by trained Fermilab personnel. To hydrogen degas the cavities, a vacuum bake cycle with a 2-hour plateau at $800^{\circ} \mathrm{C}$ is performed. The total pressure of the bake volume does not exceed 1 X $10^{-7}$ Torr. RF field flatness tuning follows. Another 1:1:2 etch of the inside surface with nominally $20 \mu \mathrm{m}$ removed is next, followed by a High Pressure Rinse and dry.

Fit up onto the vertical test stand occurs next in the A0 clean room in preparation for performance testing. To date, five cavities have passed through this stage of the process.

As results of vertical tests dictate, cavities may return for additional inside etches and high pressure rinses. To date, only cavity \#4 has passed through the sequence without requiring reprocessing. Total elapsed time for cavity processing (from completion of fabrication until ready to test) is of order 25 working days.

\section{Vertical Testing}

Each cavity is tested cold in the A0 'North Cave', a shielded, interlocked enclosure. The test setup is comprised of

- A vertical dewar containing a single cavity with instrumentation ports for RF input and output, vacuum and cryogenics connections, and diagnostics feed throughs. The cavity is mounted on a motorized stand so as to allow for variable input coupling.

- An RF system including a Traveling Wave Tube amplifier capable of providing up to 150 watts either pulsed or continuous wave, a signal generator for frequency and amplitude control, couplers, phase shifter, attenuator, etc.

- Cryogenic cooling - a stand alone 500-liter dewar of liquid helium, 2 260-liter liquid nitrogen dewars, and vacuum pumps which together can move $\sim 2.5$ gram $/ \mathrm{s}$ at 12 Torr inlet pressure. Cooling Capacity is $\sim 12$ Watts at $1.8 \mathrm{~K}$.

- Various diagnostics tools are employed for vertical testing - RF probes, platinum resistors for thermometry mounted directly on areas of interest and monitoring via a 'fast' read back system [2]. Early on, visual inspection of the inside of the dewar was deemed necessary in order to verify liquid level and to identify possible quench locations. This need has been largely usurped by the thermometry that proved to be extremely useful during investigation of HOM heating with cavity \#2. Its utility continues.
- Networked computer console running Windows supporting Labview ${ }^{\mathrm{TM}}$ applications for RF testing and Fast Thermometry monitoring and archiving.

Testing itself is largely a manual process and consists primarily of Q vs. T (during pump down from 4 to $1.8 \mathrm{~K}$ ) and $Q$ vs. E measurements. As needed, additional tests are conducted for heating, processing, and off-fundamental modes. Testing is typically completed in one 8-hour shift.

To date, Cavities \#2, 3, and 4 have been tested - a total of 15 tests. Cavities \#3 and \#4 have achieved gradients of $24 \mathrm{MV} / \mathrm{m}$ and $23 \mathrm{MV} / \mathrm{m}$, respectively. Details of these tests are reported elsewhere at this conference [3].

Table 2: Cavity Fabrication \& Testing Status

\begin{tabular}{|c|c|c|c|}
\hline Cavity & $\begin{array}{c}\text { Assembled } \\
\text { by }\end{array}$ & $\begin{array}{l}\text { Completion } \\
\text { Date }\end{array}$ & $\begin{array}{l}\text { Vertical Test } \\
\text { Results }\end{array}$ \\
\hline $\begin{array}{l}\# 1: \text {-leg } \\
\text { HOM }\end{array}$ & Fermilab & January 2006 & $\begin{array}{l}\text { Never tested - } \\
\text { HOM membrane } \\
\text { break during } \\
\text { cleaning }\end{array}$ \\
\hline $\begin{array}{l}\text { \#2: 2-leg } \\
\text { HOM }\end{array}$ & Fermilab & February 2006 & $\begin{array}{l}12 \mathrm{MV} / \mathrm{m} \text { limited by } \\
\text { HOM heating - } \\
\text { fractured Formteils }\end{array}$ \\
\hline $\begin{array}{l}\# 3: \text { 2-leg } \\
\text { HOM, } \\
\text { trimmed } \\
\text { after initial } \\
\text { tests }\end{array}$ & $\begin{array}{l}\text { Fermilab } \\
\text { JLab }\end{array}$ & August 2006 & $\begin{array}{l}24 \mathrm{MV} / \mathrm{m} \text {, achieved } \\
\text { after } \mathrm{HOM} \\
\text { trimming }\end{array}$ \\
\hline $\begin{array}{l}\text { \#4: 2-leg } \\
\text { trimmed } \\
\text { HOM }\end{array}$ & $\begin{array}{l}\text { Fermilab } \\
\text { JLab }\end{array}$ & March 2007 & $23 \mathrm{MV} / \mathrm{m}$ \\
\hline $\begin{array}{l}\text { \#5: 2-leg } \\
\text { trimmed } \\
\text { HOM }\end{array}$ & $\begin{array}{c}\text { Fermilab } \\
\text { JLab }\end{array}$ & May 2007 & $\begin{array}{l}\text { First test in late } \\
\text { June } 2007\end{array}$ \\
\hline $\begin{array}{l}\text { \#6: 2-leg } \\
\text { trimmed } \\
\text { HOM }\end{array}$ & $\begin{array}{c}\text { Fermilab } \\
\text { JLab }\end{array}$ & May 2007 & $\begin{array}{l}\text { First test in July } \\
2007\end{array}$ \\
\hline $\begin{array}{l}\# 7 \text { - single- } \\
\text { post HOM }\end{array}$ & $\begin{array}{l}\text { Fermilab } \\
\text { DESY }\end{array}$ & $\begin{array}{l}\text { In fabrication, } \\
\text { expected July } \\
2007\end{array}$ & $\mathrm{n} / \mathrm{a}$ \\
\hline $\begin{array}{l}\# 8 \text { - single } \\
\text { post HOM }\end{array}$ & $\begin{array}{l}\text { Fermilab } \\
\text { DESY }\end{array}$ & $\begin{array}{l}\text { In fabrication, } \\
\text { expected July } \\
2007\end{array}$ & $\mathrm{n} / \mathrm{a}$ \\
\hline
\end{tabular}

\section{OTHER COMPONENTS}

\section{Input Couplers}

Parts for four complete couplers have been received from the vendor and assembled into complete couplers. Remaining parts for two more required re-work by the vendor. The first pair of couplers has been installed onto a specially-designed conditioning/test stand located in the A0 SCRF facility. The stand consists of an $80 \mathrm{~kW}, 3.9$ $\mathrm{GHz}$ Klystron, modulator and charging supply, waveguide, couplers, RF signal generator, interlock system, and controls and monitoring interface. Automated controls software has been made operational for 
conditioning. Details are reported elsewhere at this conference [4].

\section{HOM Coupler Feedthroughs}

Two designs for HOM coupler feedthroughs based on DESY and JLAB experience were investigated.

The first, based on a high alumina ceramic insulator, was abandoned due to low yield and long delays from the vendor. Achieving acceptable hermetic joints between the insulator and center conductor proved difficult. Nine such pieces were received and are used for parasitic tests. Four prototypes with a sapphire insulator were obtained in a timely fashion and have achieved good results both in yield and performance during cold tests. Heating seen during cold testing underscores the need to provide for adequate thermal contact in regular operation when the feedthough will not be in a complete superfluid helium bath as is the case during vertical tets. The remainder of the order is expected shortly.

\section{Helium Vessel}

Following acceptable vertical performance testing, each cavity is fitted into a titanium helium vessel. A prototype vessel, fabricated by Fermilab, has been successfully welded to Cavity \#1. Cavities \#3 and \#4 are now ready to be outfitted. Unfortunately, the bellows to titanium welds in the vessels fabricated by an outside vendor are flawed. Improper welding techniques appear to be the root cause. Design modification and careful documentation of welding guidelines has now been done. One new vessel is being constructed in-house to have it available in as timely a fashion as possible. The remaining ones are to be fabricated by a vendor yet to be determined.

The welding process consists of a combination of several e- beam and TIG welds. Care must be taken with fixtures and weld parameters so that the cavity is not detuned or deformed. No such problems were encountered with the prototype.

\section{Tuners}

'Slow' blade tuners are employed on these cavities. The design is based on an INFN design. The tuners are driven by stepper motors designed for cryogenic and UHV conditions. Harmonic gearing provides a step ratio of 200:1.

\section{Mock-up Cavities}

With a long lead expected in dressed cavity availability, four mock-up dressed cavities have been obtained. They are proving to be invaluable in preliminary fit-up of all components, in design of shipping fixtures, and in training for final assembly. Once the cryo vessel is obtained, the mockups will be assembled into a cavity string and inserted into the vessel. The assembly will be outfitted with vibration and shock monitors and alignment fixtures, then transported around the Fermilab site in an attempt to replicate real shipping conditions. This test should prove invaluable in assuring that the completed module can be safely transported overseas. Data collected will be cross-checked with empirical data previously collected from shipping of other cavities and modeling.

\section{LESSONS LEARNED}

Attention to detail through every process has proven to be critical. In retrospect this is not surprising. It is vital that no assumptions be made as to vendor capability without first obtaining sample pieces. Careful documentation is also vital so as to provide for reproducibility in successive procedures. The use of mock-up pieces to replace long-lead, critical path components has proven to be extremely beneficial in regards to fit-up, design of assembly fixtures, and training. Lastly, a competent and well-trained processing team is critical to achieving the necessary cavity performance.

\section{SUMMARY}

Fermilab has embarked on its first significant foray into SCRF technology with the fabrication of a $3.9 \mathrm{GHz}$ cavity string for use in DESY's TTF/FLASH facility. Six cavities have been assembled and 3 have gone through vertical testing. Two have now achieved the necessary design parameters and have operated at gradients of at least 23 $\mathrm{MV} / \mathrm{m}$ with acceptable $\mathrm{Q}_{\text {ext. }}$ Two more cavities will shortly undergo the first phase of testing having completed processing. Most major components are now in hand or are due in the near future. Critical steps remain: welding into helium vessels, horizontal testing, assembly into a 4-cavity string, final assembly, and shipping to DESY. The expectation is to test the module in the DESY Module Test Facility in spring of 2008.

\section{ACKNOWLEDGEMENTS}

The authors acknowledge the significant assistance received from the staff of Jefferson Lab and particularly DESY. The dedicated efforts of the growing SRF staff at Fermilab, and especially the A0 SCRF technical support group, have been critical to the progress made to date.

\section{REFERENCES}

[1] T. Khabiboulline et al, "New HOM Coupler Design for $3.9 \mathrm{GHz}$ Superconducting Cavities at FNAL," this conference, WEPMN098.

[2] D. Orris et al, "Fast Thermometry for Superconducting RF Cavity Testing," this conference, WEPMN105.

[3] N. Solyak et al, "3.9 GHz Superconducting Accelerating 9-cell Cavity Vertical Test Results," this conference, WEPMN111.

[4] J. Li et al, "RF Design and Processing of the Power coupler for Third Harmonic Superconducting Cavities at Fermilab," this conference, WEPMN100. 